\title{
Mulheres Infames em Notícias no Oeste do Paraná
}

\author{
Infamous Women in the News in West Paraná
}

\author{
Tania Regina Zimmermann \\ Universidade Estadual do Mato Grosso do Sul \\ zimmermanntania@gmail.com
}

\section{Resumo}

Neste artigo abordam-se discursos sobre a violência perpetrada por mulheres, em notícias, no Oeste do Paraná entre as décadas de 1960 a 1980 a partir de uma perspectiva de gênero. Situações de violência tornamse um fato noticiável, sobretudo porque se contrapunham ao modelo de progresso e civilização proposto pelas elites da região. Com uma publicação quase sempre indesejada, aparecem centenas de mulheres infames. São infames porque são pessoas que dificilmente de outra forma apareceriam com corpos, rostos, nomes e, às vezes, sobrenomes nas notícias cotidianas. As ações destas mulheres estão em discursos quase sempre anedóticos, curiosos e trágicos, mas fizeram parte de histórias em sua maioria de luta e resistência mesmo com notícias que em seus jogos estratégicos construíam as desigualdades de gênero.

Palavras-chave: Violência; gênero; imprensa.

\begin{abstract}
This article delves into discourses on violence perpetrated by women, according to the newspapers in West Paraná, between the decades from 1960 and 1980, under gender perspective. Violent situations become news, especially because they go against the progress and civilization models proposed by the elites of this region. In almost undesirably published articles, we can found hundreds of infamous women. They are infamous, because they are people who otherwise would hardly appear with their bodies, faces, names and surnames in the daily news. The actions of these women figure in discourses that are often anecdotal, curious and tragic, but they were part of stories that are mostly of struggle and resistance, even in news that, in their strategic games, built inequalities of gender.
\end{abstract}

Keywords: Violence; gender; press. 


\section{Introdução}

No Oeste do Paraná, notícias construíram identificações para homens e para mulheres como, por exemplo, a violência como característica masculina e a maternidade como função exclusiva do feminino. Sentimentos como docilidade e resignação, as próprias tarefas domésticas e o espaço privado para as mulheres fizeram, e ainda fazem, com que muitas delas deixem de ser cidadãs para existirem enjauladas nas identidades femininas construídas nos discursos que enfatizam o sujeito universal masculino. Um dos exemplos desta distinção dos gêneros está no Jornal do Oeste, na matéria: 'Nem Feminismo nem Machismo: justiça'. Conforme o excerto abaixo verifico que os papéis são contrastantes nas relações de gênero:

A mulher cumpre fazer do lar um pedaço do céu, entrevisto na terra. Ali o homem retempera as forças consumidas na dura peleja travada no teatro das competições, em busca do pão de cada dia. [...] O sexo forte tira sua energia do sexo denominado fraco. Deste paradoxo depende a estabilidade da família e segurança social. [...] Os movimentos feministas têm se revelado inoperantes, pelo menos até hoje, uma vez que não conseguiram incutir na mulher, a compreensão sublime da tarefa que lhe cabe na preparação da humanidade do porvir. [...] A mulher deve permanecer naquilo que foi chamada; permanecer como rainha do lar e sacerdotisa da família. ${ }^{1}$

Outras possibilidades para os corpos e sexualidades quase sempre foram desconsideradas em discurso e, na maioria das notícias das décadas de 1960 a 1980, o tema teve pouca visibilidade. Um dos impressos de: 'O Paraná', apresenta o tema sob o título: 'Homossexualismo é ideologia'. Na matéria, segue-se a visão de Peter Fry advogando que o uso do termo é errôneo, uma vez que "essa criação cultural não existe na natureza, devendo ser abolida". ${ }^{2}$ Acredita Fry que, por não estar na ordem discursiva racional das ciências da natureza, essa criação cultural não tem nomeação. Margareth Rago expôs recentemente esta problemática da seguinte maneira:

Afinal, lembrando Baudrillard, se os americanos precisam ter a Disney para não perceber que são a própria Disney, nós precisamos ter a prisão para não percebermos que vivemos enjaulados nas identidades e classificações categoriais, nos esquadrinhamentos sociais, sexuais, espaciais, físicos e imaginários (RAGO, 2000).

Estas construções identitárias e de outras distinções sociais também adentraram a literatura e a escritura da história. Segundo Bhabha, estamos em um “[...] momento de trânsito em que espaço e tempo se cruzam para produzir figuras complexas de diferença e de identidade, passado e presente, interior e exterior, inclusão e exclusão" (BAHBHA, 2005, p.19). É nas tramas de mulheres e homens em situação de violência que também despontam algumas diferenças, exclusões, trânsitos e linhas de fuga que constroem corpos e sexos.

Documentar a vida de pessoas negligenciadas nas narrativas dos escritos abre um leque múltiplo de temas, assim como outras histórias que desmentem visões hegemônicas de mundo enaltecedoras de homens brancos, da naturalidade da monogamia, dos sentimentos, dos papéis sociais e sexuais e da certeza da inevitabilidade do progresso. Scott observa que:

O desafio à história normativa tem sido descrito, em termos de entendimentos históricos convencionais de evidência, como uma ampliação de um quadro, uma correção do que foi negligenciado como resultado de uma visão incorreta ou incompleta, e tem reivindicado legitimidade sobre a autoridade da experiência, a experiência direta de outros, bem como a do historiador que aprende a observar e iluminar a vida desses outros em seus textos (SCOTT, 1998, p.300).

Pode parecer estranho historiar a violência de mulheres, uma vez que a quantidade destas notícias no Oeste do Paraná corroboram para não priorizar tais estudos. Mas não seria ingênuo pensar que as estatísticas devam levar a um adequado tratamento qualitativo? Este é um dos aspectos observados nas pesquisas em que existem mulheres protagonistas em situação de violência. ${ }^{3}$ Diante disso, é notória a pergunta: qual é a relevância do tema? Por que dar historicidade a estas vivências? Como justificativa, apoio-me em Scott que afirma que o resgate destas situações, com seus incontáveis pequenos detalhes, permite perceber como a diferença é estabelecida entre mulheres e homens, como ela é operada em grande parte dos escritos, como e de que maneira constitui sujeitos que veem e atuam no mundo (SCOTT, 1998,p.302). Neste sentido, o estudo de jornais, revistas e noticiários de rádio em relação às violências

Tania Regina Zimmermann 
contra e das mulheres nos ajuda a entender as diferentes operações que nivelam as formas de vermos o mundo e, na pior das hipóteses, contribuir para as desigualdades de gênero.

Embora haja um destaque para a atuação de mulheres consideradas violentas nas notícias, reforçase que a violência é coisa de homens. Esta posse masculina se dá, em parte, em virtude de suas frustrações ou não, assim como a partir de condutas e práticas identificadas socialmente como masculinas e que podem estar relacionadas a experiências perigosas. ${ }^{4}$ Ainda segundo Mihaely, esta violência cristaliza todos os não-ditos e, mesmo que haja culpa e vergonha por parte dos homens diante das posições que reproduzem as relações de vítima e opressor, ainda existe uma tendência em considerar as mulheres como vítimas e os homens como biologicamente determinados à prática da violência (MIHAELY, 2006).

Os atos representados nas notícias têm, em sua maioria, a defesa de si, de familiares e da sobrevivência em relação a sofrimentos, privações e violações. Convém ressaltar que, embora a violência esteja relacionada a defesa de uma causa, ela não significa um direito a estes atos, mas, em determinados momentos, uma possível saída para opressões, sofrimentos e injustiças.

Com o cuidado para tatear as construções discursivas históricas, parto da visibilidade de algumas ações protagonizadas por mulheres postas nas notícias. Estes atos continuamente são de gente que dificilmente de outra forma apareceria com rostos, nomes e, às vezes, sobrenomes nas notícias cotidianas. Para Foucault, são vidas de algumas linhas ou de algumas páginas. Vidas breves, sistematicamente encontradas em notícias e, portanto, infames. Também o autor apresenta vidas com menos lições a serem meditadas do que vidas como daquelas histórias que os sábios recolhiam:

Pretendi também que estas personagens fossem elas mesmas obscuras; que nada as tivesse predisposto a uma qualquer notoriedade; que não tenham sido dotadas de nenhuma das grandezas como tal estabelecidas e reconhecidas - as do nascimento, da fortuna, da santidade, do heroísmo ou do gênio; que pertencessem aqueles milhões de existências que estão destinadas a não deixar rastro; [...] que, contudo, tenham sido atravessados por um certo ardor, que tenham sido animados por uma violência, uma energia, um excesso na malvadez [...] (FOUCAULT, 1992, p.97).
A vida das mulheres que matam ou que estão envolvidas em conflitos e crimes aparecem em poucas páginas, principalmente nas décadas de 1970 e 1980 . Em contrapartida, estas personagens recebem lugar de destaque nos títulos, no tamanho das letras e nas imagens fotográficas. Por que se dedicou frases, fotos e, as vezes, páginas inteiras a essas mulheres infames? Embora a violência nas relações de gênero tenha incidido principalmente sobre as mulheres, seja ela física (estupros, espancamentos e mortes) ou através de formas de violência simbólica (incapacidade política e civil, restrições da sexualidade), elas também reagiam e violentavam com ou sem instrumentos.

Para escrever histórias na quais as mulheres agiram e reagiram nas relações de violência, parto da construção de notícias sobre algumas resistências de mulheres nestes jogos de gênero. Estes jogos de gênero atravessam comportamentos, imagens, discursos e representações que conformam as relações sociais que há muito tempo vem estabelecendo hierarquias e desigualdades entre homens e mulheres. Neste jogo envolvem-se identificações, estratégias, práticas discursivas e corporais cuja compreensão dá sentido a fenômenos como a violência de gênero, ou seja, relações conflituosas entre mulheres, entre homens, entre mulheres e homens e não só entre heterossexuais, mas também entre homossexuais.

Concordo com Foucault ao afirmar que o encontro com o poder transformou os atos das pessoas infames em palavras e, posteriormente, objeto deste estudo. "Sem este choque é indubitável que nenhuma palavra teria ficado para lembrar o seu fugidio trajecto." (FOUCAULT, 1992, p.97). O mesmo poder que tentou controlar foi o poder que suscitou as palavras sobre estas vidas. E é justamente no confronto com o poder que elas encontram o único momento que alguma vez lhes foi concedido um breve clarão que as traz até nós (FOUCAULT, 1992, p.97). As mulheres infames escolhidas e analisadas nesta pesquisa podem contribuir para dialogar com o limite, o intervalo da produção de recursos da história, da linguagem daquilo que nos tornamos ou, como Hall expôs: “[...] como nós temos sido representados e como essa representação afeta a forma como nós podemos representar a nós próprios" (2000, p.109).

Ações de mulheres como protagonistas em notícias no Oeste do Paraná aparecem com notoriedade, talvez pela novidade deste tipo de comportamento, apesar de que mulheres consideradas fatais não eram novidade na literatura. Nas notícias dos jornais e da rádio estes feitos continuam a chamar a atenção até os dias atuais, mas estas mulheres praticantes de violência são consideradas infames, porque não possuem as mesmas qualificações das mulheres fatais como a beleza, magia

Tania Regina Zimmermann 
e aparecem em breves instantes.

\section{Mulheres Infames e a Violência Física e Simbólica}

As ações de mulheres em situação de violência são destaques nas notícias ao longo dos anos pesquisados. Essas mulheres são descritas como possuidoras de vidas obscuras, infelizes, raivosas, ciumentas, malfeitoras e desafortunadas. Também são relatos quase sempre anedóticos, curiosos, grotescos e que fizeram parte de inúmeras histórias minúsculas. E em grande parte das notícias, tendeu-se a tratar muitos dos casos com uma linguagem risível e em tom de deboche. Convém observar que no período em que aparece esta linguagem de deboche são frequentes as matérias relacionadas ao feminismo, principalmente após a metade da década de 1970. Esta forma de linguagem também estava presente na imprensa de oposição à ditadura militar como, por exemplo, o Pasquim, que ridicularizava a ação de feministas no Brasil (SOIHET, 2008).

Na notícia: 'A Mulher batia no marido com vara', citada abaixo, temos um exemplo de zombaria. O jornal 'O Paraná' registra um evento passado há anos e que fora comentado por um antigo político de Cascavel. O narrador descreve o texto como um teatro, seguido das seguintes cenas:

O marido após o trabalho frequentava bares da cidade de Cascavel e bebia como um gambá e sua esposa teria inventado um jeito original de conduzi-lo para casa com uma vara, conduzia o seu boi (sic) particular e amado. As cenas já eram tradicionais. A mulher vara no lombo do marido, levava não muito pacientemente o seu amado até a sua residência. Era um dia, depois do outro se formando realmente uma cena bem folclórica. Os viajantes já diziam pelos cantos do Oeste que Cascavel tinha um fato curioso: a mulher da vara. Após alguns anos o marido faleceu e não se sabe se foi das varadas ou das tremendas bebedeiras do guarda. ${ }^{5}$

Na cena a seguir, descreve-se a mulher ao lado do caixão abraçada ao cadáver e dizendo: “- $A i$, ai, ai! Pra quê ocê morreu? Nóis que nunca encrenquemo!" A notícia finda com "[...] isso aconteceu. Há testemunhas oculares, inclusive." Este discurso perpassa a estratégia da produção do verdadeiro, pois o político conta, o jornal edita e há testemunhas oculares do fato.
$\mathrm{O}$ uso frequente de adjetivos e advérbios no texto acima, como: 'já, muito, se, realmente, bem e inclusive', intensifica, neste discurso, a desqualificação das atitudes que supostamente invertem ações exclusivas de homens. Para Fairclough, a linguagem, como prática social, contribui para a dominação de umas pessoas sobre as outras. Desta forma, as práticas linguísticas estão imbricadas com o poder e a dominação. Para o autor, na redação de relatos acerca de acontecimentos, estão associados conhecimentos e posições específicas para cada tipo de sujeito social que participa desta prática (FAIRCLOUGH, 1997, p.80). Também a fala autorizada, do político no jornal, revela que o poder e a dominação estão organizados e institucionalizados e, deste modo, alguns têm acesso particular ao discurso e, como consequência, asseguram o poder de dizer algo, ou seja, quem pode falar, sobre o que, quando e como(VAN DIJK, 2004, p.3).

A notícia sobre a mulher com a vara também participa de convenções que foram e são naturalizadas como, por exemplo, a exclusividade da violência como masculina. Ao atentar para as propriedades do texto, seja no vocabulário, nas metáforas, no aspecto gramatical ou no estilo, percebe-se que algumas convenções são mecanismos eficazes de produção do senso comum que podem manter e reproduzir padrões de comportamentos. Como parte das vivências interacionais masculinas, as idas frequentes para o bar após o expediente de trabalho não deveriam ser questionadas, principalmente pelas mulheres. Mesmo que bebessem 'como um gambá', a eles permitia-se continuar com as bebedeiras que poderiam ser impossíveis de evitar, pois a medicina reconhecia ao homem o caráter autoritário, altivo, menos amoroso e mais duro(SOIHET, 1997, p.20). Quaisquer excessos deveriam ser perdoados, pois o homem era o provedor do lar, e a mulher era responsável pelo conforto em casa e pela felicidade do homem. A zombaria, em torno das atitudes de mulheres nas notícias, pretendia reforçar a fragilidade e uma suposta incapacidade de assumir os embates da vida e de assumir responsabilidades como os homens. Assim as notícias, ao trazerem atos de mulheres em situação de violência, tornavam o fato risível e, como resultado, tendia a emoldurar as identidades em padrões dados.

$\mathrm{Na}$ atuação de mulheres em situação de violência física, e posteriormente também adicionada à violência simbólica, a inferioridade é instaurada a partir das diferenças sexuais.

Deste modo, os discursos cômicos confirmam as relações de poder instituídas nas relações de gênero, visando reconstruir, nas notícias aqui apresentadas, o cotidiano perpassado pelos mitos de inferioridade e

Tania Regina Zimmermann 
domesticidade feminina.

Os discursos cômicos, nos estudos de Bakhtin, demonstram as diferenças do riso festivo popular renascentista evidenciando a igualdade, uma vez que se ria dos próprios burladores, mas a sátira moderna burguesa transforma o riso em um fenômeno particular que perpassa o caráter moralizante e hierárquico através da ridicularização. No Renascimento, através do riso se exprime a verdade na sua totalidade, mas, a partir do século XVII, a atitude em relação ao riso pode ser caracterizada da seguinte maneira:

O riso não pode ser uma forma universal de concepção de mundo; ele pode referir-se apenas a certos fenômenos parciais e parcialmente típicos da vida social, a fenômenos de caráter negativo; o que é essencial e importante não pode ser cômico. [...] O domínio do cômico é restrito e específico (vícios dos indivíduos e da sociedade); [...] o riso é um divertimento ligeiro, ou uma espécie de castigo útil que a sociedade usa para os seres inferiores e corrompidos [...] (BAKHTIN, 1987, p.5758).

Nos exemplos das notícias acima, fica evidente que algo aparentemente inofensivo como a zombaria e o deboche configuram-se como forma de violência, inoculando representações com vistas à conservação do status quo, através da ridicularização em relação aos papéis exercidos por mulheres e homens de determinados segmentos da sociedade e de espaços geográficos. Na notícia 'Inquilina do Barulho' do jornal 'Fronteira do Iguaçu', o subtítulo remete ao espaço geográfico e social da personagem principal: 'De novo aparece a Vila Coqueiral no noticiário'. Conforme a transcrição do excerto textual, pode-se observar a imagem estereotipada da personagem:

Desta feita o problema é com D. P. T., que está separada do marido e vem causando problemas a sua vizinha, pois costuma chegar altas horas, acompanhada de 'amiguinhos', ocasião que promove insuportáveis algazarras e atenta contra o pudor. [...] D. não comparece com o Tutu dos aluguéis há dois anos e com o agravante de transformar o local em verdadeiro 'rendez-vous'. Tai, agora vai entrar pela tubulação. ${ }^{6}$

A personagem acima é desqualificada por ser moradora de um bairro que é frequente nas notícias, fato este reforçado por outras características: é separada, não paga o aluguel, não é uma mulher bem comportada, pois chega altas horas e atenta contra o pudor. Nesta notícia, o pudor associa-se ao recato que consiste na boa reputação, ou seja, no respeito de si e dos outros através do sentimento de vergonha. Conforme Suarez:

Se a denúncia atrai o desprezo de outras pessoas é porque, de alguma forma e medida, as pessoas envolvidas não se fizeram respeitar ou não souberam cuidar de sua segurança. Daí conclui-se que quem deve zelar pela segurança das mulheres é cada uma das próprias mulheres [...] (SUAREZ, 1999, p.102-103).

O uso de linguagem zombeteira é recorrente quando se refere a alguns atos de moradores de bairros periféricos das diferentes cidades analisadas. Conforme Tânia Montoro, as notícias sobre violência reafirmam duas concepções morais comuns. A primeira é de que “[...] a violência é praticada por sujeitos desviantes e nos espaços marginais da sociedade." E a segunda ideia reafirma "[...] que cabe aos órgãos competentes do governo manter a sociedade limpa da violência"(MONTORO, 1999, p.107). No Oeste do Paraná, o projeto de modernização, proposto em meados do século $\mathrm{XX}$, produziu uma ordem na qual instituições como judiciário, polícia e família perpassavam um conjunto de normas e valores considerados burgueses. Nestes valores, figurava a defesa da honra e da moral, principalmente sobre as mulheres. A honra masculina relacionava-se a atitudes como valentia e coragem, a feminina se caracterizava pela defesa de sua honra por um homem. Deste modo, a honra de um homem também estava relacionada com a pureza sexual e com o pudor de mulheres de seu convívio, como esposa, filha e mãe. Neste contexto, reivindicava-se o direito de reputação moral de si, da família e do grupo social ao qual pertence.

\section{Conflitos entre Mulheres nas Notícias}

As personagens femininas presentes em notícias, por algumas linhas ou páginas inteiras, tomaram as cenas por alguns instantes. São mulheres infames e cujos atos, muitas vezes, são representados na imprensa como absurdos, loucura, anormalidade e por raras vezes monstruosidade. Estes atos de desvios quase sempre são de mulheres que dificilmente apareceriam com rostos, nomes e às vezes sobrenomes nas notícias cotidianas e, por isso emergem como

Tania Regina Zimmermann 
infames. São vidas breves sistematicamente encontradas nas páginas de jornais, revistas e demais notícias. Os instantes de aparecimento da vida das mulheres envolvidas em conflitos foram destaques na imprensa como as brigas entre vizinhas, mas noticiadas porque envolviam uma gravidez, violência contra crianças e falta de pagamento do aluguel.

Nas páginas policiais, há o registro de alguns conflitos causados por intrigas pessoais entre mulheres, sobretudo de vizinhas em locais específicos como pátios, quintais e cercas. É notório o uso de linguagem em tom de deboche no momento de reprodução da dicotomia vítima e agressora. Na notícia "Agredida moralmente pela vizinha, teve parto prematuro", são retratadas duas mulheres, uma na condição de esposa e grávida, e a outra, a agressora, como vizinha e anunciada como Frida de Tal. A agressão deveu-se pela desocupação de um imóvel da proprietária agressora e, segundo o jornal, foi o marido da vítima quem relatou o fato

[...] que a tal da Frida manda seus filhos menores dar pancadas na parede de sua casa, proferindo palavras de baixo calão contra a sua pessoa e de sua esposa e que viera agredi-la porque deseja que os mesmos deixem a casa para posteriormente alugá-la. ${ }^{7}$

Este ato é considerado na notícia como um absurdo porque a proprietária deseja a desocupação de um imóvel e usa da violência física e simbólica contra outras pessoas. O comportamento da Frida relembra para as outras mulheres a necessidade do recato, da submissão e a espera de um homem ou da justiça para resolver qualquer tipo de pendência.

Em outra notícia, sob o título 'Valentina vira Valentona', o jornal relata a agressão entre duas mulheres também devido à desocupação de um imóvel. A descrição da vítima na notícia ocorre por meio da definição do estado civil, profissão e pagamento pontual dos aluguéis. O conflito narrado é desta forma destacado:

Tudo ia na santa paz de Deus até que a esposa de seu senhorio invadiu a casa em companhia de uma filha por nome A. R. e passou a destratá-la. Dos maus tratos passou a agressão que se estendeu aos filhos menores [...] Não satisfeitas disseram que vão fazer calúnia no seu marido para que ele perca seus direitos legais. D.A. declarou que está grávida e que foi violentamente atirada contra as paredes de sua casa, o que lhe pode acarretar graves consequências $[\ldots]^{8}$
Na terceira notícia, 'Mulheres entraram no cacete', duas mulheres agridem outra mulher. Neste jornal, destaca-se que o fato tornou-se notícia a partir de um plantão policial:

J. Q., brasileira, casada, com 46 anos de idade, compareceu ao plantão policial com a cabeça ensanguentada e registrou queixa contra a sua sogra e sua cunhada M.P.Q e M. C. respectivamente, alegando a queixosa que fora espancada pelas mesmas. Dona J. foi encaminhada ao hospital para as reformas necessárias e as paraíbas responderão inquérito a respeito. ${ }^{9}$

Nestas três notícias há em comum a produção da dicotomia agressora e vítima, a perda de autocontrole e, sobretudo, a linguagem de deboche. Neste último excerto as agressoras são chamadas de paraíbas para masculinizá-las. Este tipo de linguagem também está presente em uma notícia de Matelândia, sudoeste do Paraná. O subtítulo aponta para as motivações do crime: 'Movida por um ciúme doentio, dona de casa matou garota de 14 anos'. A notícia, que ocupa toda a página, tem por título: 'Fúria assassina' e abaixo dele segue a foto de 12 por $14 \mathrm{~cm}$.

O texto destaca a repercussão do crime na cidade de Matelândia. Segundo a revista, a dona de casa abandonou os filhos e o primeiro marido devido a constante violência doméstica $\mathrm{e}$, com $\mathrm{o}$ novo companheiro, apesar de a violência ser frequente, na matéria o ato aparece apenas como um ato necessário e disciplinador.

$\mathrm{Na}$ produção da notícia, o fato motivador do crime de Feliciana é o ciúme. Este estado emocional pode ser definido como um conjunto de emoções desencadeadas por sentimentos de alguma ameaça à estabilidade ou à qualidade de um relacionamento íntimo valorizado. Soyka entende que nas sociedades em que a monogamia tornou-se um imperativo social e cultural, o ciúme foi concebido como uma proteção para a família. A modernidade deixou pouco espaço de debate para a exclusividade do sentimento de ciúme, quer seja no direito individual assim como nas relações de apaixonados. O sentimento de ciúme foi construído culturalmente como uma reação frente a uma ameaça (SOYKA, 2005, p.73) ${ }^{10}$.

Sugere-se, na matéria da 'Revista Oeste' sobre Feliciana, que as desconfianças da esposa foram fruto de 'imaginação doentia' e que o episódio poderia ser avaliado por um psiquiatra:

Se essa cena foi produto de uma imaginação doentia ou não, só um psiquiatra poderia

Tania Regina Zimmermann 
dizer. O fato é que ela reagiu como um animal. Empunhando uma faca e cega de ódio, ela pulou sobre os dois, agarrou a garota pelos cabelos e começou a apunhalála impiedosamente. ${ }^{11}$

A matéria também informa que a garota violentada procurou o marido da agressora apenas para receber o pagamento de um dia de serviço como boia-fria. $\mathrm{Na}$ necropsia, constava que a moça era virgem e que, portanto, a relação sexual com o marido só existiu na mente de Feliciana. Presa após fuga, esta não era a primeira vez que a acusada usou uma 'faca para resolver pendências pessoais'. O delegado, em depoimento à Revista Oeste, considerou o crime como brutal, cometido por motivo torpe. $\mathrm{Na}$ foto acima, destaca-se o rosto de Feliciana e a blusa com inúmeros gatos com pescoços enormes. ${ }^{12}$

Algumas palavras da notícia também indiciam os atos de Feliciana como aberrações de conduta, ou seja, a brutalidade e o fato de não conter instintos permitem associá-la a animais e a motivo torpe. O texto ainda indica que esta não foi a primeira vez que a agressora reagia com um companheiro, dado que na primeira vida conjugal abandonou o lar e crianças, sendo uma delas, na época da separação, ainda considerada bebê. $\mathrm{O}$ abandono da família e, principalmente, dos próprios filhos tende a ser punido. A maternidade relaciona-se a um 'dom natural', como apontaram os estudos de Badinter, pois uma mulher é feita para ser mãe e deve suportar sofrimentos e sacrifícios pelos filhos e toda exceção "[...] é um desafio lançado à natureza, a anormal por excelência (BADINTER, 1985, p.5). Esse modelo de sofrimento e dor segue a tradição cristã de um projeto afetivo/emocional estável entre duas pessoas que vivem em um mesmo espaço e com filhos. Grossi em seus estudos aponta para contradições nesse modelo de conjugalidade, cujos atos de violência são em parte reflexos disso e podem ser vítimas homens, mulheres, heterossexuais e homossexuais (1998, p.293-313).

Entretanto são mulheres que estão nas linhas de fuga entre a mulher contida e a mulher que age para dar fim a uma contenda, não esperando, desta forma, que os homens resolvam os seus problemas.

Os casos noticiados corroboram para a representação de que, em sua maioria, as mulheres se envolvem em futilidade e agem instintivamente. Mas o comportamento de mulheres pobres em situação de violência transgredia as margens esperadas pelos jornalistas. Os enfrentamentos cotidianos, ou seja, a luta pela sobrevivência diminuía a reclusão no lar, o culto ao amor romântico e a submissão. Suas vidas eram de intrigas, de amores, de lutas nas ruas e em suas casas, nas pequenas fábricas, de várias jornadas, de resistências e também de conformações com os valores dominantes. Mulheres estas que construíam sonhos e sensibilidades para um casamento formal e um par harmônico, e nem sempre assumiam a maternidade e as tarefas do lar como funções suas.

Pelos exemplos das notícias, percebo que escrever outras ações, que não as dadas como socialmente aceitas de homens e de mulheres em situação de violência, talvez justificasse para os jornalistas o uso de uma linguagem risível e que se traduz como uma forma de violência simbólica. Analisar esta situação revela que tornar o outro visível certamente “[...] quebra o silêncio sobre ele, desafia noções prevalecentes e abre novas possibilidades para todos"(SCOTT, 1998, p.304). Escrever sobre a história destas mulheres é tornar histórico aquilo que fora escondido da própria história. Acrescenta-se que escrever sobre mulheres protagonistas em situações de violência é escavar mais nos recônditos do humano e no aparentemente ininteligível.

1

Jornal Oeste. Nem Feminismo, nem Machismo: justiça. n. 850, 26 de julho de 1988, p. 6.

2 O Paraná. Homossexualismo é ideologia. N. 521, 6 de julho de 1976, p. 4. Este jornal foi um dos únicos a apresentar notícias com homossexuais e travestis, mas quase todas em situações de violência como no título: Travesti leva tira na boca em pleno centro de Londrina. n. 1100, 22 de janeiro de 1980, p. 8. A Tribuna. Outro detento assassinado: homossexualismo é o motivo alegado. N.58, 18 a 25 de novembro de 1983. Hoje. A agressividade dos travestis. n. 144, 19 a 25 de abril de 1980.

3 Ver obras de SOYKA, Michael. Wenn Frauen Töten. Stuttgart; New York: Schattauer. 2005; KUN, Cornelia. Ende des Schreckens. Tese em Filosofia. Oldenburg : Universität Oldenburg, 2005 e ALMEIDA, Rosemary de Oliveira. Mulheres que matam: universo imaginário do crime no feminino. Rio de Janeiro : Relume Dumará, 2001.

4 OlIVEIRA, Pedro Paulo de. A Construção Social da Masculinidade. Belo Horizonte : UFMG, 2004. p. 248. Segundo o autor o aumento dos índices de criminalidade urbana está relacionado ao reforço nos caracteres viris. p. 271.

5 O Paraná. Mulher batia no marido com 
vara. n. 520, 11 de fev de 1978, p. 11.

6 Fronteira do Iguaçu. Inquilina do Barulho. n. 106, 22 de julho de 1972, p. 16.

7 O Paraná. n. 559, 30 de março de 1978, p. 4.

8 O Paraná. n. 575. 18 de abril de 1978, p. 18.

9 Diário do Oeste. n. 420, 15 de setembro de 1968 , p. 6.

10 Analba Brazao Teixeira discute brevemente a historicidade do ciúme em sua obra: Nunca você sem mim. São Paulo : Anablume, 2009, p. 58.

11 Revista Oeste. Fúria Assassina. n. 48, maio de 1989, p. 29.

12 Idem, ibidem.

\section{Referências}

ALMEIDA, Rosemary de Oliveira. Mulheres que matam: universo imaginário do crime no feminino. Rio de Janeiro : Relume Dumará, 2001.

BHABHA, Homi. K. O local da Cultura. Belo Horizonte: Editora da UFMG, 2005.

BAKHTIN, Mikhail. A Cultura Popular na Idade Média e no Renascimento: o contexto de François de Rabelais. São Paulo: Hucitec, 1987.

CALDAS-COULTHARD, Carmen Rosa. Linguagem e estudos de gênero. In: FORTKAMP, Mailce Borges Mota; TOMITH, Lêda Maria Braga (Orgs). Aspectos da Lingüística Aplicada. Florianópolis: Insular, 2000, p. $273-287$.

FOUCAULT, Michel. O que é um autor? Lisboa: Veja, 1992.

História da Sexualidade II: O Uso dos Prazeres. 6.ed. Rio de Janeiro: Edições Graal, 1984.

FAIRCLOUGH, Norman. Discurso, mudança e hegemonia. In: PEDRO, Emilia Ribeiro. (org.) Análise Crítica de Discurso. Lisboa: Caminho, 1997, p. 77 103.

HALL, Stuart. Quem precisa de identidade? In: SILVA, Tomaz Tadeu da (org.) Identidade e
Diferença: a perspectiva dos estudos culturais. Rio de Janeiro: Vozes, 2000, p. 103 - 131.

KUN, Cornelia. Ende des Schreckens. 2005. Tese em Filosofia - Universität Oldenburg, Oldenburg.

MACHADO, Lia Zanotta; MAGALHÃES, Maria T. $\mathrm{B}$ de. Violências Conjugais: os espelhos e as marcas. In: SUÁREZ, Mireya; BANDEIRA, Lourdes (Orgs.) Violência, Gênero e Crime do Distrito Federal. Brasília: UnB, 1999, p. 215 - 251.

MIHAELY, Gil. Masculinidades: corpo, natureza e poder. (Texto traduzido após palestra na UFSC) Florianópolis, 2006. (s/p).

MONTORO, Tânia. Notícias de Violência: uma leitura. In: SUÁREZ, Mireya; BANDEIRA, Lourdes (orgs.) Violência, Gênero e Crime do Distrito Federal. Brasília : UnB, 1999, p. 105 - 126.

OLIVEIRA, Pedro Paulo de. A Construção Social da Masculinidade. Belo Horizonte: UFMG, 2004.

RAGO, Margareth. Pensar diferentemente a história, viver femininamente o presente. In: GUAZELLI, Cesar A.B. et al. (Org.) Questões de Teoria e Metodologia da História. Porto Alegre: Editora da Universidade/UFRGS, 2000, p. 41 - 58.

SOIHET, Rachel. Preconceitos nas Charges de O Pasquim: mulheres e a luta pelo controle do corpo. Revista Espaço Acadêmico, n. 84, maio de 2008. [Disponível em <www.espacoacademico.com.br/ 084/84soihet.htm> Acesso em 10 de abril de 2009]

Violência Simbólica: saberes masculinos e representações femininas. Revista Estudos Feministas. v. 5, n. 1, 7-29, 1997.

SUÁREZ, Mireya. O Discurso Policial Comentado. In: SUÁREZ, Mireya; BANDEIRA, Lourdes (Orgs.) Violência, Gênero e Crime do Distrito Federal. Brasília. Brasília. Brasília: Paralelo 15 / Editora da Universidade de Brasília, 1999, p. 57-104.

SCOTT, Joan. A Invisibilidade da Experiência. Projeto História, n. 16, p. 97-325, 1998.

SOYKA, Michael. Wenn Frauen Töten. New York: Schattauer. 2005.

VAN DIJK, T. Analisis Critico del Discurso. [Disponível em <www.meus 
documentos/documentos/ARTIGOS/cátedra/UNESCO

> Acesso em 24 de abril de 2004]

WOLFF, Cristina. Feminismo e Configurações de Gênero na Guerrilha: perspectivas comparativas no Cone-Sul, 1968-1985. Revista Brasileira de História, vol. 27, n. 54, p. 19-38, 2007.

ZIMMERMANN, Tânia Regina. Violência e Gênero em Notícias no Oeste Paranaense (1960-1990). 2010. Tese (Doutorado em História) Universidade Federal de Santa Catarina. Florianópolis, Santa Catarina. 